\title{
Introduction to the symposium on feminist perspectives on human-nature relations
}

\author{
Daniela Gottschlich ${ }^{1} \cdot$ Tanja Mölders $^{2} \cdot$ Martina Padmanbhan $^{3}$ (I)
}

Accepted: 18 November 2016/Published online: 24 November 2016

(C) Springer Science+Business Media Dordrecht 2016

Ever since sustainable development has been discussed as a gendered issue, the United Nations Conference on Environment and Development (UNCED) in 1992 recognized the centrality of gender equality, women's empowerment and the realization of women's rights to achieve sustainable development (UN 2014). Following this idea of sustainable development as an integrative concept means needing to take both nature and society into consideration. Although the gender dimension of sustainable development has been generally accepted, the current trend towards green economy cannot seriously claim to be gender sensitive nor has it broken with the paradigm of economic growth and does not appear to be striving towards equal and democratic forms of shaping human-nature relations (Gottschlich et al. 2014; Harcourt and Nelson 2015). Thus, in response to the recent Rio20+ debate, there is an evident need to further explore and engage in developing the vital links between social, economic and environmental research. In this context, we

Martina Padmanbhan

martina.padmanabhan@uni-passau.de

Daniela Gottschlich

gottschlich@diversu.org

Tanja Mölders

t.moelders@archland.uni-hannover.de

1 Economic and Social Geography, Faculty of the Regional and Environmental Research, Universität Trier, Campus II, Behringstr. 21, 54286 Trier, Germany

2 Institute of Architectural History and Theory, Leibniz Universität Hannover, gender_archland, Herrenhäuser Str. 8, 30419 Hannover, Germany

3 Lehrstuhl für Vergleichende Entwicklungs- und Kulturforschung (Schwerpunkt Südostasien), Universität Passau, Dr.-Hans-Kapfinger-Straße 14b, 94032 Passau, Germany stress the importance of theorizing and conceptualizing human-nature relations from a critical feminist perspective, grounded in empirical research.

Within the framework of sustainable development, perspectives from the Global South and North have become important, as feminist contributions to the political debate on sustainable development over the last 25 years have shown. In response to the marginalization of feminist concerns in the sustainability discourse, however, feminist thinkers have been challenged to differently link their ideas to ongoing debates on sustainable development.

In this symposium, our main area of interest is sustainability in the rural context, addressing social-ecological problems of livelihoods and political action in rural areas. We propose feminist theoretical approaches and concepts, which seek to demystify human-nature relations as they have been seen from a productivist stance. The overall aim is to bring knowledge of the mutual construction of nature and gendered socio-economic relations out into the open, thereby contributing towards building sustainable human-nature relations. More specifically, this symposium seeks to make the analytical and epistemological potential of feminist research available for interdisciplinary research on agriculture and human values in rural development. We have found it important to gather empirically grounded work from the Global South and North and to examine our assumptions from a comparative perspective, as we now do in this editorial.

The papers gathered together for this symposium were originally presented during various sessions at different international conferences dealing with sustainable development from a broad perspective. First, in 2012, Martina Padmanabhan organized a session on "The social organization of agrobiodiversity-Reconfiguring gender relations in times of environmental crisis" at the World Congress of 
Rural Sociology in Lisbon, Portugal, where Annemarie Burandt and Tanja Mölders as well as Isabelle Kunze and T.R. Suma and Christina Großmann presented their papers. Second, Daniela Gottschlich presented previous versions of her paper in 2012 at the "Planet under Pressure" conference in London, UK, and at the 2013 Congress of the European Society for Rural Sociology in Florence, Italy, before she invited Leonie Bellina to be co-author. Finally, in 2013, the German Geography Conference in Passau, Germany, provided an audience for the paper of Michaela Schöley and Martina Padmanabhan. The papers are here complemented by an essay by Wendy Harcourt, narratively linking individual gender perspectives with theoretical approaches on feminist human-nature relations.

The results presented in this symposium have been derived from research carried out by two junior research groups within the German funding program for SocialEcological Research (SOEF). ${ }^{1}$ Between 2008 and 2014 the projects BioDiva ${ }^{2}$ (leader: Padmanabhan) and $\mathrm{PoNa}^{3}$ (leaders: Gottschlich and Mölders) analyzed human-nature relations in agriculture-related areas in India and the EU. Within the social ecology approach adopted by the researchers who participated in these projects, human-nature relations are conceptualized as being societal relations to nature, aiming to overcome naturalistic or socio-centric reductionism within this relationship. Further the inter- and transdisciplinary approach of SOEF has served as a unique perspective in being sensitive about gender issues with regard to both organizational and content considerations (Schultz et al. 2015). As the social-ecological approach does not follow a core gender theory, we will unfold the theoretical approaches and concepts that have been relevant for us in the following.

\section{Theoretical approaches and concepts}

Feminist scholars have engaged in a long debate concerning the connections between women, often under the category of gender, and nature. Following Butler (1990), we may even speak of "nature trouble" in contemporary research exploring linkages between societal relations to gender and nature. Feminists have developed various theoretical approaches and concepts in order to explain the human-nature nexus, ranging from essentialist to constructivist approaches. A simple summing up of this heterogeneous field illustrates at least a twofold connection: First, both women - their work, knowledge, bodiesand nature experience similar social devaluation and

\footnotetext{
${ }^{1}$ http://www.fona.de/en/9883.

2 http://www.uni-passau.de/en/biodiva/home/.

3 http://www.pona.eu.
}

economic exploitation, focusing primarily on their "reproductive" capacity. Women and nature are constructed as the "other" over which male subjects, patriarchal institutions and the capitalist economy may dispose. Second, nature is often cited as an argument for justifying social differences (e.g. inclination to care work) so that hierarchies can remain unchallenged by moving them into the sphere of nature.

In light of these connections, we might differentiate those approaches and concepts that we feel are located precisely at the interface of gender and nature as being core theories regarding feminist perspectives on human-nature relations. In line with Hofmeister et al. (2013, p. 78 ff.), we identify ecofeminism, feminist ecological economics and gender and environment as three key perspectives that have been historically constitutive for the emergence of this field of research, containing crucial discourses for enlightening the nexus between gender, nature, society and sustainability. Ecofeminism makes the connections between women, ecology and nature a subject of discussion not only from an essentialist point of view-as is often assumed - but from various theoretical and empirical perspectives (in particular, Kunze in this symposium). Feminist ecological economics criticizes economic rationalities and the ignoring of processes of social reproduction and unpaid work in mainstream economics (in particular, Gottschlich and Bellina). The gender and environment approach applied here (in particular, Burandt and Mölders) is related to the German SOEF program and needs to be distinguished from other ideas commonly associated with it internationally (Biehl 1991). We also suggest adding feminist political ecology as a fourth fundamental research area analyzing the ideological framing of the co-construction of gender and the environment (in particular Harcourt, Kunze and Suma and Grossmann).

In addition to these research areas and related feminist theories that focus on human-nature relations, we want to underline here that the central categories and dichotomies that feminist theories deal with in general (e.g. production vs. reproduction, public vs. private) are fruitful for the deconstruction of inherent gender hierarchies within the sustainable development discourse. Thus, current debates about the category care suggest a bridging perspective within the triangle of nature, society and gender (in particular, Gottschlich and Bellina, see also Well and Gradwell 2001). This also applies to the intersectional extension of feminist theory via further categories of social relevance (race, class, ability, sexual orientation, religion, caste, class etc.; Carstensen-Egwuom 2014). This seems to be especially true with regard to (empirical) studies in the Global South, where intersections between forms or systems of oppression, domination or discrimination form a rich and complex window for social-ecological crises (in particular, Schöley and Padmanabhan as well as Kunze). 
Finally, we identify sustainability sciences and development studies as seminal perspectives for analyzing the human-nature nexus from a feminist perspective. This is because the question of gender relevance is-at least programmatically_an inherent part of both research areas. Taking into account the papers presented here, we would like to mention the environmental justice approach as an often marginalized line within sustainability sciences (Gottschlich and Bellina). With regard to our focus on rural development and agriculture, revisiting the moral economy of the peasant, highlighting the centrality of subsistence, could also prove to be beneficial (Kunze). Moreover, we would like to draw attention to spatial perspectives in sustainability studies discussing the relationship of physical (place) and social (space) construction, such as under the category of the politics of place (Harcourt).

In sum, we believe that feminist perspectives on humannature relations can serve as an eye-opening means for examining the hierarchical social relations between gendered humans and nature. The fact that these hierarchies are stabilized by everyday practices, institutional settings and the dominant strand of the sustainable development discourse itself, as well as current measures of its implementation, makes it difficult to deconstruct them. Nonetheless, we argue that the dismantling of such existing gender hierarchies is crucial for overcoming social devaluation and injustice in human-nature relations.

\section{Rethinking methodology}

Researching human-nature relations from a feminist perspective has an impact in terms of choosing appropriate methodological procedures to apply. Feminist theoretical interest in the entanglement of categories referring to the social and natural spheres bears epistemological consequences, as we have become aware of how our gaze shapes the subject matter. Thus Haraway's (1988) notion of situated knowledge prepares the ground for methodological disclosures (Harcourt) and reflections on positionality (Kunze). As descriptive and normative knowledge emerges from situated life, it is imperative to take this embeddedness of social action into account for feminist analysis. Furthermore, only within this situatedness is gender played out in power and knowledge relations. On the one hand, Harcourt emphasizes in her contribution the specificity of perspectives stemming from politics of place and resulting in differing points of view. On the other hand, she appropriates scientific enquiry as her own personal quest when engaging in oral history, focusing on conversing "with" interviewees, and gradually moving further into action as a result. In problematizing gendered divisions of labor, organizational structures and politics, Harcourt becomes part of the struggle over what
Haraway (2003) calls "naturecultures". Harcourt's "methodological disclosure" contradicts reigning conventions regarding the anonymity of respondents and, rather, literally takes interviewees as partners on a joint journey. Situating herself as an involved outsider, she illuminates her stake in the writing and unveils her position in the process of (counter-) knowledge creation. Research can then become a form of resistance, the building of a counterculture in conservative rural areas and take part in coopting and re-appropriating gendered social-ecological relations. In Harcout's case, research into the place-specific daily lives and practices of gendered human beings like the consumption of agrobiodiversity can become an emancipatory opportunity for transformative politics.

In the same vein, Kunze and Padmanabhan (2014) have engaged elsewhere with the intersectionality of their own positionalities in the field, discussing how methods reflect power and lead to a tendency to undervalue predefined power relations. From their perspective, language and cultural barriers, ethnic background and class standing do influence outcomes. Consequently, instead of asking for ideal application of neutral and objective methods, timeand context-dependency are taken as a source of epistemological gain. A researcher's biographical subjectivity, point of entry into the field, the body as a marker of identity, marital status and the relationship between researchers and assistants can influence the generation of data and its analysis. Co-authorship between a Southern and Northern researcher can also influence the knowledge produced. For this volume, based on intricate ethnographic fieldwork by an Indian-born social activist turned scientist and informed by the ideas of a theoretically versed German, two social anthropologists became engaged during the processes of data generation, analysis, and writing in the co-production of knowledge (Suma and Grossmann).

\section{Comparative perspectives, conceptualizing gender}

We find it not only important to create research environments that bring together Southern and Northern perspectives but also to gather empirically grounded work from the Global South and North to examine our assumptions from a comparative perspective. Here we consider European perspectives alongside cases in India so as to guard against simplified and essentializing depictions of harmonious human-nature relations in the South. At the same time, taking a global perspective reminds us, as scholars from different disciplinary backgrounds and traditions, to be aware of our own positionalities and terminologies.

The twofold strategy of letting theory speak to praxis via empirically grounded research and vice versa enables particular forms of knowledge acquisition. Theoretical 
saturation and the description of human-nature relationsbe it via feminist political ecology or ecofeminism-helps to detect patterns of social interaction and dynamics in empirical cases. At the same time, confrontation with ambiguous data forces us to sharpen and differentiate terms. For example, the category of subjectivity helps to demystify the idea dominant in the literature of the solitary guardian role of women in conservation but also brings to fore their desire to find their own place within changing agrarian relations.

Similarly, the transdisciplinary nature of these inquiries-aimed at integrating actors' perspectives into the knowledge-creation process (Jahn et al. 2012) - urges researchers to consider informants not merely as data sources but rather as active agents shaping issues and framing human-nature relations in their own right. Selfdeclared traditional male farmers and clandestine female innovators are actively involved in the co-production of knowledge when presenting and commenting on preliminary results from their own perspectives. In fact, a cyclical development of terminology is initiated through the mutual influence of empirical actualities on pre-existing definitions, the latter's further refinement according to evidence, followed again by their renewed application as transdisciplinary categories (Padmanabhan 2016).

Conceptualization of gender differs between papers in the symposium, unfolding the breadth of analytical approaches and richness of theorizing on human-nature relations offered here. Still, taking gender as a category of difference, thus focusing on sex as a marker for men and women, appears as a necessary tool to analyze, for example, the continually perpetuated gendered division of labor revealed in Harcourt's Italian case or the differing perspectives on subsistence and commodity production put forward by Burandt and Mölders.

Distinguishing between sex and gender is, foremost, a reaction to the dominant rhetoric of naturalizing women, a means to question the nature versus culture paradigm and its inherently hierarchical perspective on gender relations. The notion of gender signals that the dualism man versus woman should not be merely taken as a biological given but rather as a socially created distinction that is, thus, subject to change. In this symposium, we conceptualize gender along four complementary dimensions: Following Moeckli and Braun (2001) gender is viewed as a process, ${ }^{4}$

\footnotetext{
${ }^{4}$ Gender as a process category is an outcome of the social interaction of individuals, which (re)produces gendered subjectivities in every encounter. Research questions here center on the discursive and institutional process of constructing the norms for what it means to be "normal" men and women. One is, here, rather "doing" than "being" gender. In this tradition, the feminist critique of the natural sciences focuses on scientific ways of naturalizing gender and influencing the construction of difference.
}

structural $^{5}$ and relational category, ${ }^{6}$ to which we add gender as an epistemological category ${ }^{7}$ for scrutinizing the production of knowledge (Harding 1986; Schiebinger 1989, 2001).

Juxtaposing cases from the Global South and North enables us to reflect on inherent assumptions and, at the same time, opens up new feminist perspectives on the shared issue of human-nature relations in at least three ways: The view from the North, firstly, raises the important question of who is interested in maintaining certain identities, such as women as born innovators or protectors of nature, and exploring how these images are linked to conserving the patriarchal blueprint or opening avenues for new gendered human-nature relations. Second, consideration of intersectionality underlines the importance of considering property rights over land, the resulting types of farm businesses and the encoded gender relations involved. Third, posing the question of environmental justice can help to mutually shed light on blind spots in the North as well as in the South. Results from the South highlight the impact of education and how the power to frame the human-nature issue accordingly has real-world consequences. While education mobilizes aspirations and extends gendered perceptions, the situation in the area of control and access continue to stand still.

\section{Emerging issues in sustainable rural development}

Virtually throughout the symposium, agrobiodiversity emerges as a boundary object ${ }^{8}$ for exemplifying and illustrating the material as well as symbolic aspects of human-nature relations. Its dual character as an expression of natureculture-biological organisms molded by

\footnotetext{
$\overline{5}$ Gender as a structural category is recognized as a principle of organizing society, positioning men and women in hierarchical relationships. Therefore, it is important to consider both men and women in the analysis of social and political institutions and how their relationships are shaped and enforced.

${ }^{6}$ Gender as a relational category sets an analytical focus on differences, hierarchies and exclusions in societal arenas, taking also into account specific contexts and the organization of intimacy in areas such as the body, health and reproduction. This perspective is especially applicable for transdisciplinary enquiries, as the construction of gender relations appears as a result of the interaction of lifeworld perceptions and scientific knowledge in their specific cultural, historical and political expressions.

${ }^{7}$ Gender as an epistemological category focusses on the production of knowledge and differentiates between various theoretical approaches-beginning from "Women in Science" up to "Doing Gender while Doing Science".

${ }^{8}$ Boundary objects allow researchers as well as activists to collaborate in inter- and transdisciplinary ways on common tasks (Bergmann et al. 2010, pp. 65, 106ff.).
} 
centuries of social and value-driven selection and utilization-even resonates in Gottschlich and Bellina's call for environmental justice regarding reproductive care.

Political as well as scientific analysts acknowledge the key role of women in the maintenance of agrobiodiversity, as women "may well be the largest human group dedicated to conserving and developing plant genetic diversity" (Schäfer et al. 2002, p. 13). While tending nature, women are also active in the social sphere when they ensure the food security of their households or take responsibility for their family's health needs. Thus the connection between nature and society becomes once more evident and humannature relations also appear as gender relations. Therefore, it is of utmost importance to deconstruct these relationships as gendered relations via a focus on intersectionality. Taking this project forward, we here identify emerging fields in the practices and research of sustainable rural development.

Practices involved in human-nature relations, such as management and selection of seeds, access to land for cultivation and necessary reproduction tasks usually categorized as non-market activities, are deeply associated with-sometimes contradictory-images of gender. Analytically linking and deconstructing the gendered ideologies attached to the existing gendered division of work will remain an important task for arriving at a helpful understanding of human-nature relations. Building, then, on non-ideological accounts of such relations is likely to set the potential free for just sustainability strategies that can move beyond the conservative women in development approach. Ignoring, for example, complex gendered power structures by devising women-only programs has tended to leave men's privileges untouched, resulting in their monopolies being reconfirmed.

Sustainability in general asks for context in the sense of values and social constituencies as well as ecological dynamics and is the reference point for devising local versions of a "sustainability to come" (Gottschlich 2013). In this context, the importance of place in relation to space and the body emerge again as promising avenues for exploring meaning and action in specific situations. But engagement with values should not deflect from the fact that the norms understood as pertaining to sustainability are subject to contestation and negotiation. Moreover, debate over contradictory aims and means is part and parcel of reconciling the goals of social, economic and ecological well-being in the long run. Thus, the search for a good life involves implicit and explicit contestation over changing values. Transformation can be observed in, for example, slow culture as a form of food politics. As some of the articles in this volume seek to demonstrate, through the consumption of agrobiodiversity in the forms of cheese, wine and rice, men and women can re-appropriate their relation to nature. This ultimately bears consequences for livelihoods which, in the Global North as well as in the Global South, are being confronted with centralized agrofood regimes. These still adhere to a productionist perspective on agriculture, which rests on the assumption that agrobiodiversity will continue to be provided and maintained forever as a coproduction of small-scale and subsistence farming.

\section{Contributions to the symposium}

The symposium begins with a theoretical contribution, as Daniela Gottschlich and Leonie Bellina propose that the perspectives of still-marginalized discourses that specifically address the interdependencies of social inequities and ecological unsustainability (human-human-nature relations) can substantially increase the transformative potential of sustainability as a discourse and praxis. The paper presents some contributions of feminist and environmental justice analysis-specifically, care and a plural conceptualization of justice-and critically engages with normative assumptions regarding economy and equity in the dominant sustainability discourse through those lenses. The authors argue that, when environmental justice and care "are both considered to be socio-ethical categories central to the functioning of sustainable societies", becoming "guidelines for governance", they function as powerful levers and strategies for transformation. A key focus for such a critical-emancipatory conception of sustainable development is overcoming the existing gendered separation (and its inherent hierarchy) of production and reproduction.

The examination of separation processes and their effects on agrobiodiversity is also the starting point of the second contribution to this symposium. Annemarie Burandt and Tanja Mölders conceive agrobiodiversity as an example of nature-gender relations within agrarian change that have become characterized by separation processes such as conservation versus use or subsistence versus commodity production. They argue that the European Common Agricultural Policy, despite its claim of taking an integrated policy approach, does not necessarily overcome such separation tendencies and, in the end, the integration of the productive and the reproductive spheres has rather failed-both in terms of nature and gender. Reproductive processes remain subordinated under productive ones or have to be commodified in order to be valued. Against this background, Burandt and Mölders demand "new rural economic rationalities characterized by processes whose qualitative, material and value dimensions maintain agrobiodiversity."

Following the two theoretical contributions of the members of the PoNa research group, three empirical 
studies based in South India-conducted by members of the BioDiva research group-further enrich our analysis of human-nature relations. While the study of Michaela Schöley and Martina Padmanabhan considers the seed system of a district in the state of Kerala as a multi-ethnic case, the other two inquiries, written by Isabelle Kunze and T.R. Suma and Kristina Grossmann, each zoom in on discursive and practical negotiations over gendered nature-relations for a single ethnic group: the Adivasi Kuruma and Kuriychia peoples, respectively. These tribal communities follow distinct social patterns that have evolved around rice cultivation. Interestingly, gender appears as the dominant marker distinguishing seed networks in the area, while ethnicity seems to explain the differing degrees of integration between formal and informal seeds systems.

Schöley and Padmanabhan focus on agrobiodiversity as an explicit outcome of a long-lasting human-nature relationship. The aim of their paper "is to understand this changing relationship under formal and informal institutional settings and to explore effects of such settings on performance and their consequences for men and women in rice seed systems." Based on network analysis, they investigate the organization of seed management and exchange in Kerala, employing an interactive method to identify important actors in the seed system and the characteristics of their relationships. Schöley and Padmanabhan not only look into the gendered structure of information regarding seed varieties and actual seed transactions but also reveal a number of unsolved problems concerning seed sources, while seeking to show from a gendered perspective how informal and formal seed systems coexist and arguing that their degree and areas of overlap are shaped by gendered human-nature relations.

Meanwhile, Kunze analyzes the contradictory dualisms emanating from the commonly taken for granted assumption ascribing women a closer relationship with nature than men. By investigating discursive links among the Kuruma ethnic group, deconstructing the making of gender and nature, she has been able to unravel the discrepancies in this image, wherein the assumed closeness of women to nature dissolves in everyday life. Moreover, while denying women any significant agricultural knowledge, male Kuruma still emphasize their identity as traditional farmers in sharp contrast to modern agriculture, whereas women define themselves increasingly in terms of education, mobility and off-farm income. Thus, the cultivation of landraces is being accompanied by contradictory moral judgments and de facto management decisions.

In the Kurichyia community, renowned for its conservation activities related to rice varieties, Suma and
Grossmann show an even more complicated picture of gendered relations to nature. Although Kurichya women have vast knowledge about rice cultivation, they cannot use it for actively cultivating rice on their own, as they have no access to traditional rice seeds and land in the rainy season. Suma and Grossmann demonstrate that development intervention launched by the state have not brought betterment in women's control over land and seeds and have failed to increase women's empowerment and food security, arguing that "integration and enhancement of the traditional knowledge of Kurichya women in the state-designed Joint Liability Groups has not been taking place, as it promotes high-yielding seeds and fertilizers". While men act as gatekeepers over traditional seeds within the hierarchical joint family, women now serve as entry channels for high-yielding varieties on their very own plots. Thus, their vast ecological knowledge remains untapped and seemingly irrelevant.

The three Indian cases complement each other, by showing that women form the vital linkage between formal and informal seed systems. Nevertheless, their emerging agency is unfolding in ways that are making their local social-ecological seed systems more permeable. While men promote themselves as traditional agriculturalists, women embrace new options and horizons. Women can thus be perceived here as gate openers, with men functioning as gatekeepers. Synthesizing these findings, we need to underline that young women in the South will not "naturally" be guardians of agrobiodiversity for its own sake. Rather, as women move out of their natal homes or bring in new ideas from outside and, via reinterpretation, create a bioeconomy on their own terms. While women try an escape within the system, men remain and conserve their social structure by controlling access to resources, meaning here access to seeds.

The symposium closes with an essay by Wendy Harcourt which brings us back to the Global North and key changes in societal relations taking place in Bolsena, a Tuscan region in Italy that has been facing a dramatic decline of traditional local agricultural practices since the 1990s. Through the narratives of three women, who differ in terms of their understandings regarding care of the self, community and environment, Harcourt explores how gender dynamics have shifted with the changing values and livelihood opportunities of Bolsena. By listening to the stories of these three women, their everyday lives and struggles, Harcourt reveals aspects of the dynamic potential of the politics of place, including "the creation of new possibilities of being-in-place and being-in-networks with other human and non-human living beings" and how they can be linked to "efforts to build more ethical economic and ecological relationships based on gender-aware subjectivities and values". 


\section{Rethinking sustainability in theory and practice}

The guiding economic principle of most modern capitalist societies is externalization - with destructive consequences for livelihoods and food sovereignty all around the world. Modern capitalist economies generally rely on so-called reproductive resources (care/subsistence work and nature), which are exploited by the market economy but not normally reproduced. Economic enterprises often operate under the assumption of being allowed to externalize social and environmental burdens and costs of production (in spatial as well as intra- and intergenerational terms) and thrive on the continued violation and exploitation of particular social groups, their labor, knowledge and time. Although power relations and hierarchies are, thus, at the core of social-ecological change, existing knowledge production is still virtually incapable of addressing them. Despite the calls for interdisciplinary thinking becoming stronger and stronger, gender (conceived in an intersectional manner, as we have outlined above) as a relevant category for addressing relations of domination is still being marginalized.

The contributions of this symposium seek to show that feminist perspectives on human-nature relations can help to frame questions that are adequate to the complexity of the problems at hand and to explore existing conflicts. Research that strives to transcend disciplinary orientations has to take into account the gendered dimension of social and economic practices, cultural patterns and values, state policies and, importantly, forms of access and control over natural resources.

Feminist perspectives on human-nature relations are manifold. As already described above, the papers we present in this symposium are rooted in feminist political ecology and social ecology. Most of them take an explicitly intersectional feminist approach in asking how changing environmental conditions are related to certain categories of inequality. As Suma and Grossmann elaborate, the focus lies in multifocal power relations in political economies, processes of commodification, and changes in women's labor conditions, especially in terms of access and control. All papers collected here have in common that they aim to tackle gendered power structures without simplifying and essentializing women's roles in them. Neither is, for instance, unpaid care work only a female task nor is the guarding of agrobiodiversity a quasi-natural competency of women. Contributions from this symposium seek to deconstruct the myth of women having a special relationship with the environment. Moreover, they examine political and economic dependencies as well as social hierarchies and consider everyday actions to answer the following questions: How do people come to care for and shape societal relations to nature? How can women's activities towards preserving agrobiodiversity be reconsidered analytically and be politicized in a way which neither romanticizes nor devalues women's agroecological expertise, knowledge, skills and care work? And how can treating women as a homogenous group and continuing to essentialize naturalized assumptions about the genders be avoided?

The contributions to this symposium aim to provide means for answering these questions. To us, they demonstrate the theoretical and practical relevance of current discussions on how to achieve socially just human-nature (gender) relations by working towards dissolving old dichotomies beyond male and female, Global North and Global South, production and reproduction, conservation and use, nature and culture so as to eventually achieve sustainability.

Acknowledgements The fruitful cooperation between the two research groups that have developed most of the articles collected here-BioDIVA: Transformation-Knowledge towards a GenderEquitable and Sustainable Use of Biodiversity and PoNa-Shaping Nature: Policy, Politics and Polity-would not have been possible without the financial support of the German Federal Ministry of Research and Education (BMBF). We, thus, thank the BMBF for its generous funding (BioDIVA 01UU0908 and PoNa 01UU0903). We would like to acknowledge the community members who participated in all research processes. Our warm thanks to all the authors of this symposium for their stimulating contributions. We would like to express our gratitude to all anonymous reviewers for their helpful comments. We also thank Regina Treipl, Regina Kaltenbach, Michael Colshorn, Jana Koltzau and Pia Kühnemann for their support in carrying out many tasks necessary for the publication of this symposium. And last but not least, we are very grateful to Christopher Hank for language-editing support.

\section{References}

Bergmann, M., T. Jahn, T. Knobloch, W. Krohn, C. Pohl, and E. Schramm. 2010. Methoden transdisziplinärer Forschung. Ein Überblick mit Anwendungsbeispielen. Frankfurt am Main: Campus Verlag.

Biehl, J. 1991. Finding our way. Rethinking ecofeminist politics. Montreal, New York: Black Rose Books.

Butler, J. 1990. Gender trouble: Feminism and the subversion of identity. New York: Routledge.

Carstensen-Egwuom, I. 2014. Connecting intersectionality and reflexivity: methodological approaches to social positionalities. Erdkunde 68(4): 265-276.

Gottschlich, D. 2013. Kommende Nachhaltigkeit. Bausteine für ein kritisch-emanzipatorisches Konzept nachhaltiger Entwicklung aus feministischer, diskurstheoretischer Perspektive. Osnabrück: Universität Osnabrück.

Gottschlich, D., S. Roth, A. Härtel, U. Röhr, S. Hackfort, D. Segebart, and C. König. 2014. Sustainable economy between gender, care and green economy. Debates-interfaces-blind spots. CaGE texts No. 1. http://www.cage-online.de. Accessed 26 Feb 2015.

Harding, S. 1986. The science question in feminism. Ithaca, New York: Cornell University Press. 
Haraway, D. 1988. Situated knowledges: The science question in feminism and the privilege of partial perspective. Feminist Studies 14(3): 575-599.

Haraway, D. 2003. The companion species manifesto. Dogs, people, and significant otherness. Chicago: Prickly Paradigm Press.

Harcourt, W., and I.L. Nelson (eds.). 2015. Practicing feminist political ecologies. Moving beyond the 'green economy'. London: Zed Books.

Hofmeister, S., C. Katz, and T. Mölders (eds.). 2013. Geschlechterverhältnisse und Nachhaltigkeit. Die Kategorie Geschlecht in den Nachhaltigkeitswissenschaften. Opladen, Berlin, Toronto: Barbara Budrich.

Jahn, T., M. Bergmann, and F. Keil. 2012. Transdisciplinarity: Between mainstreaming and marginalization. Ecological Economics 79(7): 1-10.

Kunze, I., and M. Padmanabhan. 2014. Discovering positionalities in the countryside: Methodological reflections on doing fieldwork in South India. Erdkunde 68(4): 277-288.

Moeckli, J., and B. Braun. 2001. Gendered natures: Feminisms, politics, and social nature. In Social nature. Theory, practice, and politics, ed. N. Castree, and B. Braun, 112-126. Oxford: Blackwell.

Padmanabhan, M. 2016. Intraface: Negotiating gender-relations in agrobiodiversity. In Special Issue: (Bio-) Diversity, Gender and Intersectionality. Freiburger Zeitschrift für GeschlechterStudien (fzg). 22(2): 85-105.

Schäfer, C., M. Gutiérrrez, L. Lemp, G. Henne, and A. Müller. 2002. The convention on biological diversity. Ensuring gender sensitive implementation. Eschborn: GTZ.

Schiebinger, L. 1989. The mind has no sex? Women in the origins of modern science. Cambridge: Harvard University Press.

Schiebinger, L. 2001. Has feminism changed science?. Cambridge: Harvard University Press.

Schultz, I., E. Schramm, and D. Hummel. 2015. Gender als Integrationsdimension in der transdisziplinären SÖF (sozialökologischen Forschung). In Nachhaltigkeit anders denken. Veränderungspotenziale durch Geschlechterperspektiven, ed. C. Katz, S. Heilmann, A. Thiem, L.M. Koch, K. Moths, and S. Hofmeister, 217-230. Wiesbaden: Springer.

UN. 2014. Gender Equality and Sustainable Development. World Survey on the Role of Women in Development 2014.
Well, B.L., and S. Gradwell. 2001. Gender and resource management: Community supported agriculture as caring-practice. Agriculture and Human Values 18(1): 107-119.

Daniela Gottschlich holds the Chair of Economic and Social Geography as a visiting professor at the University of Trier. Before she taught Political Ecology at the Free University of Bozen-Bolzano, Italy and was temporary professor for "Climate Change and Sustainable Development" at the Geography Department of Humboldt-Universität zu Berlin. Previously, she has co-leaded the research group "PoNa-Shaping Nature: Policy, Politics and Polity" with Tanja Mölders at Leuphana University Lüneburg. She holds a Ph.D. in Political Science from University of Osnabrück, Germany. Her research areas are Political Ecology, Feminist Economics, Postcolonial Studies, social-ecological transformation, democratization of societal nature relations and transdisciplinarity.

Tanja Mölders holds the chair "Space and Gender" at the Leibniz University Hannover. There she co-operates with the research initiative "gender_archland", a unique forum for gender competence in architecture and landscape planning. Here main interests are gender and environment studies, gender and spatial development, rural gender studies and the nexus of space, place and body. She received her $\mathrm{Ph} . \mathrm{D}$. in environmental studies at the Leuphana University Lüneburg. There she has co-leaded the research group "PoNaShaping Nature: Policy, Politics and Polity" with Daniela Gottschlich.

Martina Padmanabhan holds the chair in "Comparative Development and Cultural Studies" with a focus on Southeast Asia at the University of Passau, Germany. She holds a Diploma in Agricultural Sciences and a Ph.D. in Rural Sociology from University in Göttingen. She received her venia legendi for Rural Sociology from Humboldt University Berlin. Her research focuses on social-ecological research, gender studies, institutional analysis, sustainable development and the theory and practice of transdisciplinary research. She has conducted empirical fieldwork in Ghana, Ethiopia, Indonesia and India. 